\title{
The asthma-COPD overlap syndrome: how is it defined and what are its clinical implications?
}

\author{
This article was published in the following Dove Press journal: \\ Journal of Asthma and Allergy \\ 10 February 2016 \\ Number of times this article has been viewed
}

Maarten van den Berge ${ }^{1,2}$

René Aalbers ${ }^{3}$

'Department of Pulmonary Diseases, University Medical Center Groningen, University of Groningen, ${ }^{2} \mathrm{GRIAC}$

Research Institute, University Medical

Center Groningen, University of Groningen, ${ }^{3}$ Department of

Pulmonary Diseases, Martini Hospital, Groningen, the Netherlands
Correspondence: Maarten van den Berge Department of Pulmonary Diseases, University Medical Center Groningen, University of Groningen, Hanzeplein I, 9700 RB Groningen, the Netherlands Tel +3I 50 36I 5260

Email m.van.den.berge@umcg.nl
Abstract: It is increasingly recognized that both asthma and chronic obstructive pulmonary disease (COPD) are heterogeneous diseases with a large inter-individual variability with respect to their clinical expression, disease progression, and responsiveness to the available treatments. The introduction of asthma-COPD overlap syndrome (ACOS) may lead to a better clinical characterization and improved treatment of patients with obstructive airways disease. However, it is still in its early phase and several improvements will have to be made. First, a clear definition of ACOS and preferably also its sub-phenotypes, eg, asthma-ACOS and COPD-ACOS, is urgently needed. That would also allow researchers to design clinical studies in well-defined patients. The latter is important since the interpretation of clinical studies performed so far is hampered by the use of many different definitions of ACOS. Second, future studies are needed to investigate the role of state-of-the-art techniques such as computed tomography, genetics, and genomics in the phenotyping of patients with obstructive airways disease, ie, asthma, COPD, and ACOS. Third, longitudinal studies are now needed to better define the clinical implications of ACOS with respect to the long-term outcome and treatment of ACOS and its sub-phenotypes compared to only asthma or COPD.

Keywords: ACOS, asthma, COPD, inflammation, remodeling, overlap phenotype

\section{Introduction}

Asthma and chronic obstructive pulmonary disease (COPD) are highly prevalent chronic lung diseases with a strong personal and economic impact. Typically, allergic asthma presents at an early age after constitutional eczema and allergic rhinitis, the so-called allergic march. ${ }^{1}$ Asthma patients report variable symptoms of wheezing, cough, and dyspnea, as a consequence of bronchial hyperresponsiveness (BHR) and airflow obstruction that is fully reversible after treatment with a bronchodilator. The underlying pathology in asthma is predominantly characterized by a Th2-driven eosinophilic airway inflammation that is responsive to treatment with inhaled corticosteroids (ICS). ${ }^{2}$ In contrast, COPD usually presents in smokers or ex-smokers after the fourth decade of life. COPD patients report continuous symptoms of dyspnea, cough, and sputum production and display chronic airflow obstruction that is not, or only partially, reversible after bronchodilator treatment and slowly progressive over time. The underlying pathology in COPD is characterized by a predominantly Th1 - and Th17-driven inflammatory process with increased numbers of cytotoxic CD8+ lymphocytes, neutrophils, and TGF- $\beta$-induced fibrosis of the (small) airways and poorly responds to ICS treatment. ${ }^{3}$ In their pure form, it is easy to distinguish between asthma and COPD. However, in real life, patients often have overlapping clinical features of 
both which makes it difficult to establish a clear diagnosis of either asthma or COPD. For example, asthma patients can have features of COPD with a history of smoking, evidence of neutrophilic airway inflammation that is poorly responsive to ICS treatment, or development of a fixed airflow obstruction. Conversely, COPD patients may present with characteristics that are traditionally attributed to asthma, such as evidence of eosinophilic inflammation in their sputum or blood, or a marked improvement in their lung function after administration of a bronchodilator. It has been estimated that $15 \%-50 \%$ of patients with obstructive airway diseases older than 50 years show a mixture of criteria for both asthma and COPD. ${ }^{4,5}$ Since this large group of patients has been systematically excluded from clinical studies, there is hardly any scientific information available about their diagnosis, treatment, and prognosis. This problem is increasingly recognized and recently described in a joint publication by the Global initiative for chronic Obstructive Lung Disease (GOLD) and the Global Initiative for Asthma (GINA) committees as the asthma-COPD overlap syndrome (ACOS). ${ }^{4,5}$

The Lancet wrote in an editorial in April 1965 “... few diseases have been surrounded by such diagnostic confusion as those whose clinical feature are cough, sputum, and breathlessness with wheezing, which are variously described as asthma, chronic bronchitis or emphysema". ${ }^{6}$ Actually not much has changed since then.

In this manuscript, we will review the clinical features, diagnosis, definition, and treatment implications of the ACOS syndrome.

\section{Definition of the ACOS syndrome}

The joint GINA and GOLD publication does not provide a clear definition for the ACOS syndrome. ${ }^{4,5}$ It defines eleven clinical features that can be scored and, if present, favors the diagnosis of asthma or COPD. The eleven clinical features are described in detail in Table 1 and are related to 1) age of onset of the disease, 2) pattern of symptoms, 3) lung function, 4) lung function between symptoms, 5) past history (previous doctor's diagnosis of asthma or COPD, history of tobacco smoking) and family history of asthma or allergy, 6) time course (seasonal symptoms, improvement after treatment with a bronchodilator or ICS, progressive worsening over time), and 7) chest X-ray. The presence of three or more clinical features listed for either asthma or COPD, in the absence of those for the alternative diagnosis, supports a correct diagnosis. ACOS should be considered when "a similar number of features listed for asthma and COPD are present".
This definition for ACOS is not yet very specific as it is recognized that a more detailed classification of patients with overlapping features of asthma and COPD is needed. Studies performed so far have used different criteria to define ACOS (Table 1). Generally, the ACOS syndrome has been defined as one of two clinical phenotypes:

1. Never-, ex-, or current smokers with a history of asthma who have incompletely reversible airflow obstruction. We will refer to these patients as asthma-ACOS in this manuscript.

2. Smokers or ex-smokers with COPD according to the GOLD criteria who display increased bronchodilator reversibility or BHR. We will refer to these patients as COPD-ACOS in this manuscript.

\section{Clinical features}

Studies performed so far have generally based the diagnosis of ACOS on the pattern of symptoms, presence of incompletely reversible airflow obstruction in ex- or current smokers or patients with asthma, degree of bronchodilator reversibility, and BHR.

\section{Symptoms}

It is difficult to differentiate asthma and COPD based on respiratory symptoms. It is clear that an acute onset of wheeze and dyspnea after allergen exposure is compatible with asthma. However, symptoms as chronic cough and/or sputum production, usually attributed to COPD, are frequently reported in patients with asthma as well especially in those who have developed fixed airflow obstruction. ${ }^{7}$ In COPD, symptoms of chronic cough and sputum production are associated with a worse outcome, ie, greater decline in lung function, more frequent exacerbations, and even mortality. ${ }^{8-10}$ It has been suggested that this may be the case in asthma as well. Lange et al reported that the presence of chronic mucus hypersecretion is associated with a greater decline in forced expiratory volume in the first second $\left(\mathrm{FEV}_{1}\right)$ in 778 patients with self-reported asthma, both in males and in females and irrespective of smoking status. ${ }^{11}$ A subset of COPD patients report symptoms historically attributed to asthma, ie, episodic breathlessness and wheezing, especially those who smoke more. ${ }^{12}$ It has been suggested that the presence of such "asthma-like" symptoms in COPD is associated with increased eosinophilic airway inflammation and a favorable response to ICS treatment. ${ }^{13}$ Although this has so far been shown in one small study in only 17 patients with COPD, the presence of eosinophilic airway inflammation in COPD patients who display asthma-like symptoms is of interest as it may suggest a favorable ICS treatment response. 


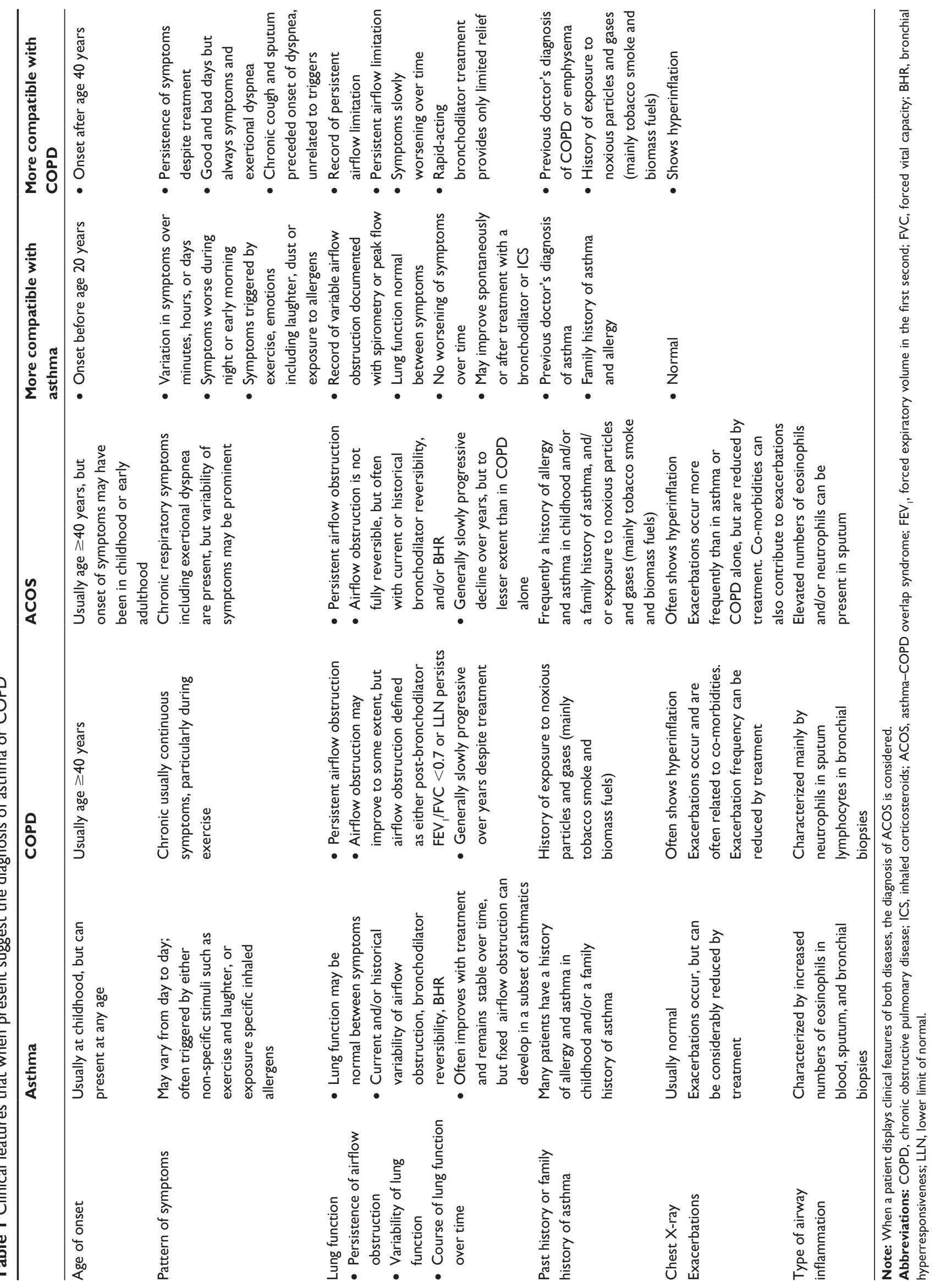




\section{Airway remodeling and development of fixed airway obstruction in asthma}

Morphometric studies have revealed that the airway wall of asthma patients is characterized by an increased thickness involving goblet cell and mucus gland hyperplasia, a thickened area below the basement membrane, smooth muscle hyperplasia and hypertrophy, and increased vascularity. ${ }^{14}$ Together, these changes are referred to as "airway remodeling". The presence of airway remodeling is associated with airway obstruction, BHR, and a more severe asthma. ${ }^{15}$

On the long term, a subset of asthma patients develops a fixed airflow obstruction. ${ }^{11,16}$ It has been shown by Vonk et al that $16 \%$ of asthmatic patients will develop fixed airway obstruction over time. ${ }^{16}$ Fabbri et al demonstrated that the type of inflammation and remodeling in asthma patients with fixed airway obstruction is different from that seen in COPD patients. ${ }^{7}$ Patients with asthma who developed irreversible airflow obstruction later in life have significantly more eosinophilic inflammation measured in blood, sputum, bronchoalveolar lavage fluid, and airway mucosa and a thicker reticular basement membrane compared to patients with smoking-related COPD with a similar degree of airflow obstruction. ${ }^{7}$ During a follow-up period of 5 years, patients with asthma and irreversible airflow obstruction had a greater rate of lung function decline compared to the control group with fully reversible airflow obstruction, their rate of decline being similar to that observed in patients with COPD. ${ }^{17}$ Interestingly, higher sputum eosinophil counts and nitric oxide levels were found to predict lung function decline in patients with asthma and irreversible airflow obstruction, whereas elevated sputum neutrophil counts, higher emphysema scores, more co-morbidities, increased exacerbation frequencies, and lower diffusion capacities were associated with lung function decline in COPD.

\section{Bronchodilator reversibility}

A large improvement of the airway obstruction after treatment with a bronchodilator, ie, increase in $\mathrm{FEV}_{1} \geq 200 \mathrm{~mL}$ and more than $12 \%$, is frequently considered as a key characteristic of asthma. However, during the last decade, it has become increasingly clear that bronchodilator reversibility can occur in up to $50 \%$ of patients with COPD as well. ${ }^{18} \mathrm{In}$ addition, bronchodilator reversibility is not present in all asthmatics. For example, a bronchodilator will not have a large effect in asthma patients who are well controlled and already have a normal lung function to start with. Thus, bronchodilator reversibility alone is not a useful tool to differentiate between asthma and COPD. Several studies have investigated whether the presence of bronchodilator reversibility provides information on prognosis or treatment response in COPD. The ECLIPSE study demonstrated that the presence of bronchodilator reversibility is not related to exacerbation frequency, rate of lung function decline, or mortality in COPD. ${ }^{19}$ One small study by Papi et al suggested the presence of bronchodilator reversibility in COPD to be associated with eosinophilic airway inflammation in COPD. ${ }^{20}$ Several studies investigated the association between bronchodilator reversibility and treatment responsiveness to ICS. ${ }^{21-23}$ Bleecker et al showed in a large group of COPD patients that the improvement in post-bronchodilator $\mathrm{FEV}_{1}$ after 8 weeks treatment with fluticasone/salmeterol 250/50 $\mu \mathrm{g}$ BID was significantly greater in COPD patients with $(\mathrm{n}=161)$ vs without $(\mathrm{n}=197)$ bronchodilator reversibility. ${ }^{21}$ This is in agreement with the findings of Kitaguchi et al who found a significantly larger improvement in $\mathrm{FEV}_{1}$ after $2-3$ months of treatment with ICS in COPD patients with vs without bronchodilator reversibility, mean improvements in $\mathrm{FEV}_{1}$ being 359 and $168 \mathrm{~mL}$, respectively. ${ }^{22}$ By contrast, two further studies did not demonstrate a difference in ICS responsiveness between COPD patients with and without bronchodilator reversibility. ${ }^{23,24}$ However, these latter two studies were small and hampered by a lack of power.

\section{$\mathrm{BHR}$}

BHR is a core feature of chronic obstructive airway diseases. In asthma, a more severe BHR is associated with a higher number of exacerbations, and increased eosinophilic airway inflammation. ${ }^{2,25}$ Although BHR is often considered to be specific for asthma, it has been shown to occur in up to $60 \%-90 \%$ of patients with COPD as well. ${ }^{26-28}$ It has been argued that BHR is not of pathophysiological importance in COPD as it would merely reflect a lower pre-challenge $\mathrm{FEV}_{1} .{ }^{29}$ However, this does not appear to be the case, since we showed in a multivariate regression analysis that a more severe BHR in COPD is independently associated with airway inflammation as reflected by the number of neutrophils, lymphocytes, and macrophages in induced sputum and bronchial biopsies. ${ }^{26}$ In addition, the presence of BHR precedes the development of COPD in the general population $^{30}$ and a more severe BHR in COPD predicts a higher rate of lung function decline even when adjusted for baseline $\mathrm{FEV}_{1} \cdot{ }^{27,31}$ One small study showed that COPD patients who exhibited hyperresponsiveness to the indirect stimulus mannitol $(\mathrm{n}=7)$ had a significantly greater improvement in $\mathrm{FEV}_{1}$ after 3 months treatment with ICS when compared to COPD patients without hyperresponsiveness 
to mannitol $(n=30)$. However, this contrasts with the findings of Rutgers et al who did not find any improvement in $\mathrm{FEV}_{1}$ after 6 weeks treatment with budesonide $1,600 \mu \mathrm{g}$ daily in COPD patients with hyperresponsiveness to both methacholine and adenosine $5^{\prime}$-monophosphate which is an indirect stimulus. ${ }^{32}$ Thus, BHR measurements alone do not differentiate between asthma.

\section{Clinical presentation, prognosis and pharmacological treatment of ACOS}

Hardin et al investigated subjects included in the COPD Gene study who had all smoked more than 10 packyears, an $\mathrm{FEV}_{1} /$ forced vital capacity $\left(\mathrm{FVC}\right.$ ) ratio $<70 \%$ and $\mathrm{FEV}_{1}$ $<80 \%$ predicted. ${ }^{33}$ They were considered to have ACOS when a doctor's diagnosis of asthma before the age of 40 had been reported. ${ }^{33}$ According to this definition, 796 subjects had pure COPD and 119 ACOS. Patients with ACOS had a worse health-related quality of life and experienced more frequent exacerbations. In addition, they had more air trapping measured with inspiratory and expiratory computed tomography scans. In another study, Kauppi et $\mathrm{al}^{34}$ based a diagnosis of asthma and COPD on British guidelines and American Thoracic Society and European Respiratory Society criteria, respectively, and divided patients into three groups: those with asthma only $(n=1,084)$, those with COPD only $(n=237)$, and those with $\operatorname{ACOS}(n=225)$. Asthma patients were significantly younger than those with COPD, had a better lung function and less co-morbidities such as hypertension, cardiovascular diseases, and diabetes. ${ }^{34}$ Despite the fact that ACOS patients fell between the groups with respect to these characteristics, they had a significantly worse healthrelated quality of life compared to those with either asthma or COPD only. ${ }^{34}$ Thus, ACOS patients have more frequent exacerbations, worse quality of life, and more respiratory symptoms compared to patients with asthma or COPD. Most studies performed so far had a cross-sectional design and therefore little is known about the clinical outcome of ACOS. There has been a study by Fu et al who followed 55 patients with ACOS over a period of 4 years and compared the course of disease to 36 patients with COPD and eight asthmatics. ${ }^{35}$ ACOS was defined as COPD GOLD stage II or higher and either bronchodilator reversibility or BHR. At baseline, there were no differences in functional status ( $\mathrm{St}$ George's Respiratory Questionnaire (SGRQ) and 6 Minute Walking Distance [6MWD]), comorbidity (cardiovascular dysfunction and Charlson Comorbidity Index), and ICS use among patients with ACOS, asthma, or COPD. During the 4-year follow-up, post-bronchodilator $\mathrm{FEV}_{1}, 6 \mathrm{MWD}$, and SGRQ significantly decreased in patients with COPD, but not in those with ACOS or asthma. ${ }^{35}$ The decline in 6MWD was the greatest in the COPD group and significantly different compared to the ACOS and asthma groups. Thus, patients with ACOS may have a favorable long-term clinical outcome even though they have a higher burden of disease.

With respect to the pharmacological treatment of ACOS, the clinical phenotype may be important. Responsiveness to ICS and long-acting beta-agonists may be different in asthmatics who have developed fixed airflow obstruction, asthma-ACOS, vs patients with COPD who display asthmatic features, COPD-ACOS. Tashkin et al showed in a post hoc analysis of two double-blind randomized, placebo-controlled studies that patients with asthma-ACOS experienced a better improvement in their $\mathrm{FEV}_{1}$ after 12 weeks treatment with budesonide or budesonide/formoterol, but not with formoterol monotherapy, compared to placebo. ${ }^{36}$ Thus far, very little is known about the short- and long-term effects of ICS treatment on the different components of airway remodeling. Several studies have reported that ICS treatment lasting for a period between 6 weeks and 2 years decreases basement membrane thickening, although this has not been consistently found in all studies.

Two studies have investigated ICS treatment responsiveness in patients with COPD-ACOS. Kitaguchi et al showed that patients with ACOS had a better improvement in $\mathrm{FEV}_{1}$ after 2-3 months of treatment with $400 \mu \mathrm{g}$ fluticasone/day compared to those with COPD alone. ${ }^{13}$ In a retrospective study, Lim et al investigated the long-term treatment responsiveness in patients with COPD-ACOS and showed that the annual rate of lung function decline in COPD-ACOS patients who were prescribed ICS ( $\mathrm{n}=90)$ was similar when compared to those who did not receive ICS $(n=35)$ during a maximum follow-up duration of 12 years, the mean (95\% confidence interval) annual decline in $\mathrm{FEV}_{1}$ being $-7.3(-34.2 ; 5.1)$ $\mathrm{mL}$ vs $-14.6(-17.9 ; 3.4) \mathrm{mL}$, respectively, $P=0.52$. However, in a sub-analysis they found that COPD-ACOS patients who received an ICS prescription for at least $75 \%$ of days $(n=13)$ during a minimum follow-up period of 4 years tended to have a better lung function over time compared to those who received ICS treatment less consistently, the mean annual rates of $\mathrm{FEV}_{1}$ decline being $-17.5 \mathrm{vs}-26.3 \mathrm{~mL}$, respectively, $P=0.059 .{ }^{37}$

Taken together, the currently available evidence suggests that ICS should not be withheld in asthma-ACOS, since it is characterized by eosinophilic airway inflammation and shortterm ICS treatment leads to improvement in $\mathrm{FEV}_{1}$. However, 


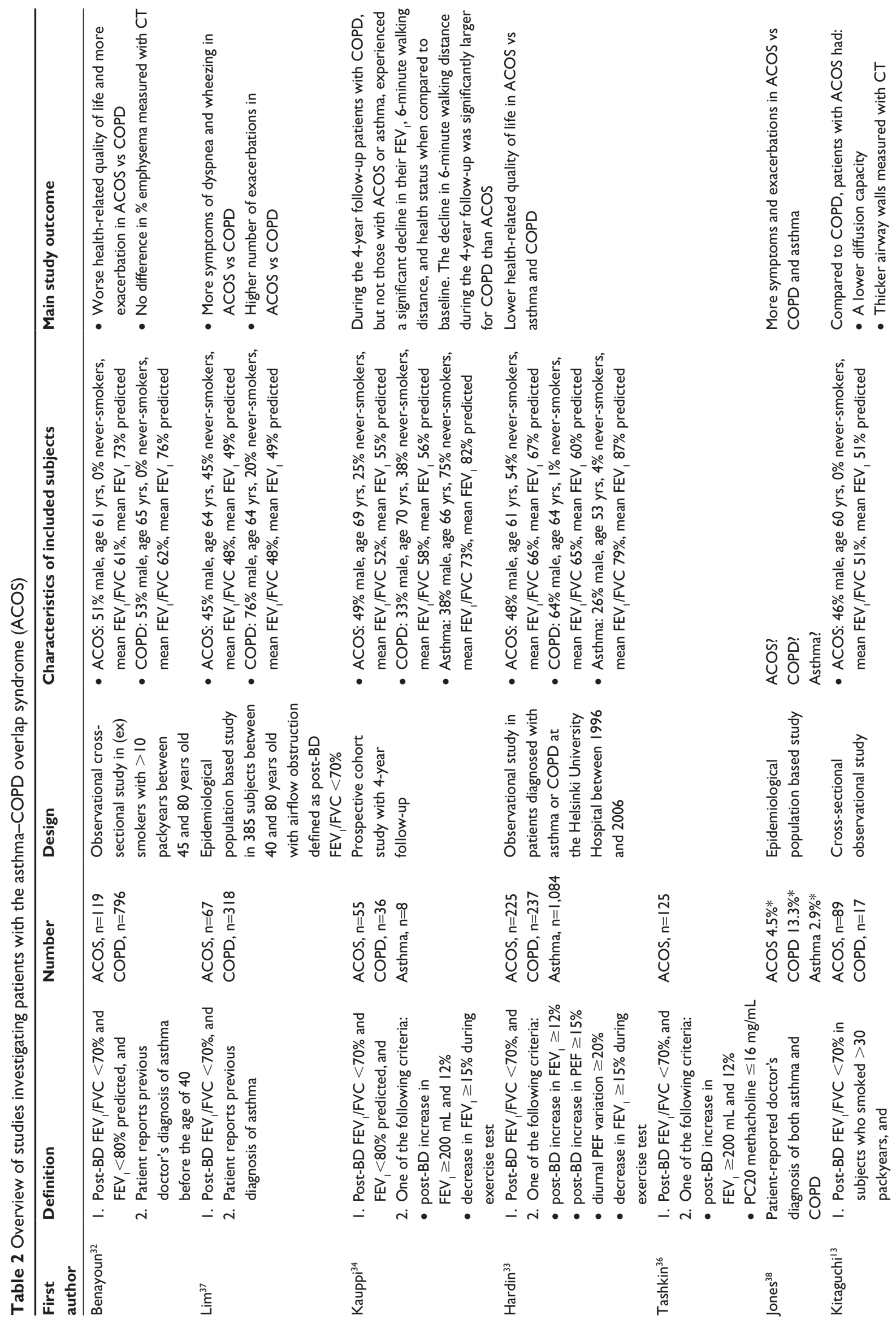




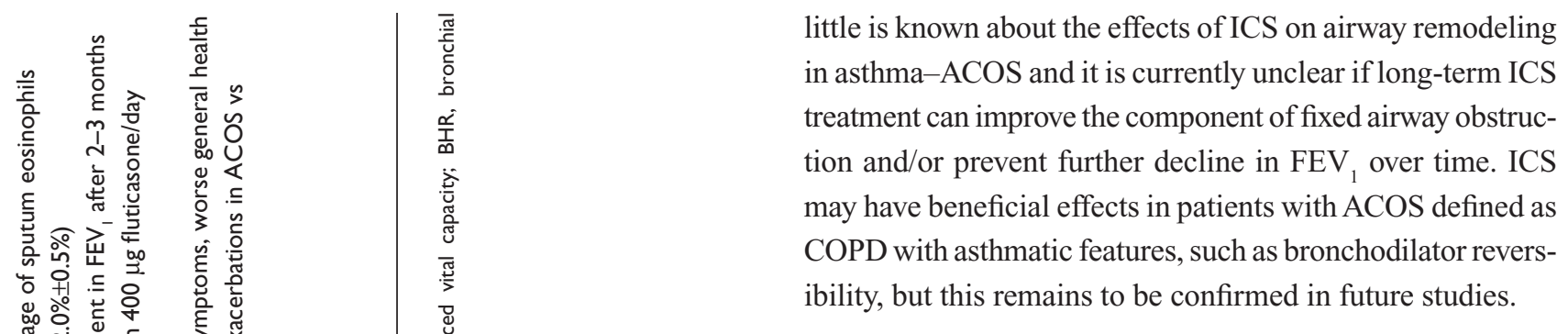

\section{Summary and conclusion}

It is increasingly recognized that both asthma and COPD are heterogeneous diseases with a large inter-individual variability with respect to their clinical expression, disease progression, and responsiveness to the available treatments. The introduction of ACOS may lead to a better clinical characterization and improved treatment of patients with obstructive airways disease. For example, adult asthmatics with fixed airflow obstruction are frequently labeled as COPD and unjustly denied ICS. ${ }^{38}$ This is now prevented, since clinicians will now diagnose these patients with ACOS. In addition, a better phenotyping in COPD may help to identify those COPD patients who benefit from ICS treatment. The latter is important, because there has been a trend toward increased cautiousness toward initiating treatment with ICS, since they are associated with an increased risk of developing pneumonia in COPD. Although the introduction of the ACOS syndrome is a step forward, it is still in its early phase and several improvements will have to be made. First, a clear definition of ACOS and preferably also its sub-phenotypes, eg, asthma-ACOS and COPD-ACOS, is urgently needed. That would also allow researchers to design clinical studies in well-defined patients. The latter is important since the interpretation of clinical studies performed so far is hampered by the use of many different definitions of ACOS. The latter is illustrated by Table 2 which presents an overview of the definitions and main outcomes of studies performed so far. Second, despite the current availability of state-of-the-art techniques such as computed tomography, genetics, and genomics, the definition of ACOS as proposed in the current GINA/GOLD document is solely based on symptoms, lung function, and chest X-ray. This is surprising, since there is an increasing amount of evidence from clinical studies showing that the presence of eosinophilic airway inflammation in sputum and blood predicts which COPD patients will have a favorable response to treatment with ICS with fewer exacerbations and improvement in FEV at least over a short-term period of up to 12 months. ${ }^{39,40}$ In this context, our recent findings are also of interest. ${ }^{3}$ We evaluated genes, previously reported to be associated with Th2-high asthma in two independent cohorts of patients with COPD. ${ }^{3}$ 

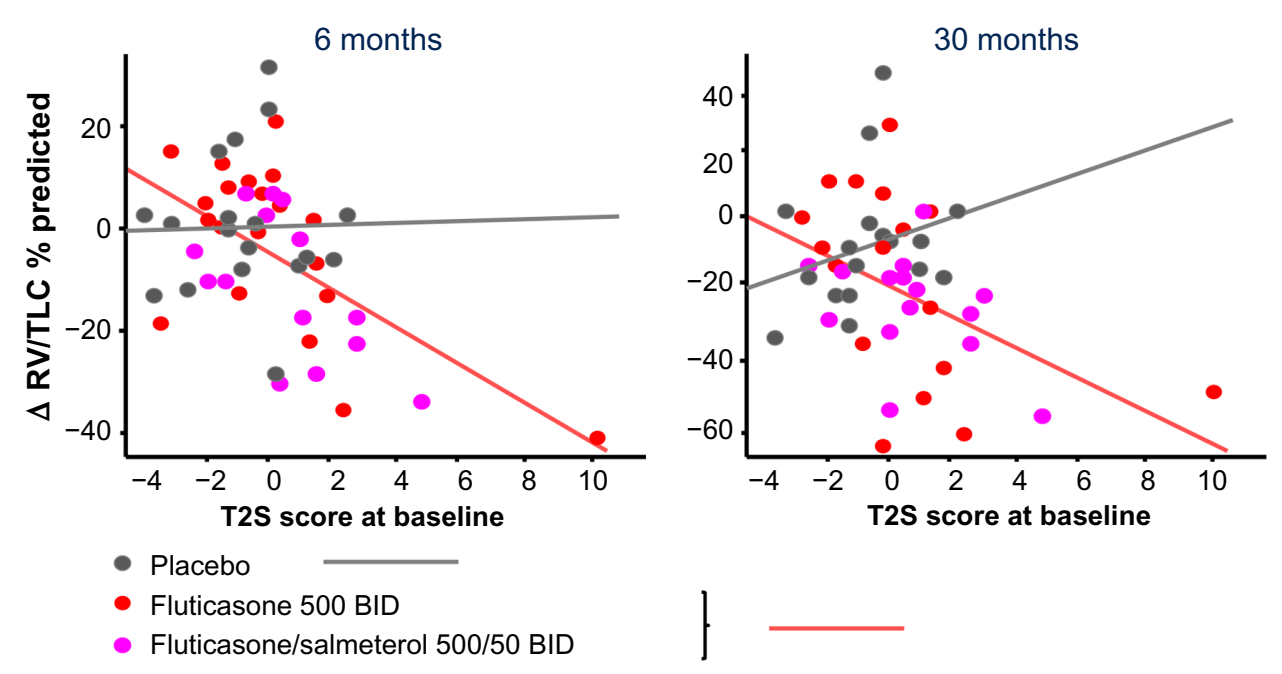

Figure I Relationship between Th2 Signature Score at baseline and improvement of hyperinflation after 30 months of treatment with inhaled fluticasone with or without added formoterol. Increased baseline Th2 score predicts a greater decrease in RV/TLC \% predicted in the treatment group compared to placebo, $t$-value $-2.43, P=0.019$. Notes: Reprinted with permission of the American Thoracic Society. Copyright @ 2015 American Thoracic Society. Christenson SA, Steiling K, van den Berge M, et al. 20I5. Asthma -COPD overlap. Clinical relevance of genomic signatures of type 2 inflammation in chronic obstructive pulmonary disease. Am J Respir Crit Care Med. Volume 191(7), pages 758-766. ${ }^{3}$ The American Journal of Respiratory and Critical Care Medicine is an official journal of the American Thoracic Society.

Abbreviations: RV, residual volume; TLC, total lung capacity.

The 100 genes most up-regulated in the airway epithelium in Th2 high asthma as compared to Th2 low asthma/healthy controls were summarized into a single Th2 composite score using a principle component analysis projection algorithm. ${ }^{3}$ COPD patients with a higher Th 2 composite score had a more severe airflow obstruction and displayed asthmatic features, ie, increased eosinophilic inflammation in their blood and bronchial biopsies, and bronchodilator reversibility. Moreover, they had a favorable treatment response: after both short-(6 months) and long-term (30 months) treatment with inhaled fluticasone with or without added salmeterol, they experienced more improvement in hyperinflation, measured with body plethysmograph compared to COPD patients with a low Th2 composite score (Figure 1). These findings are promising as they show that the presence and extent of "Th2driven eosinophilic inflammation" is a useful biomarker to guide the diagnosis of asthma, COPD, or ACOS. Future longitudinal studies are now needed to better define the clinical implications of ACOS with respect to the long-term outcome and treatment of ACOS and its sub-phenotypes compared to only asthma or COPD.

\section{Acknowledgment}

We would like to thank Bettie Goud for her valuable contribution to this manuscript.

\section{Disclosure}

MvdB reports research grants paid to University Medical Center Groningen from Chiesi, GlaxoSmithKline, AstraZeneca, and TEVA Pharma. RA has no conflicts to disclose.

\section{References}

1. Postma DS, Reddel HK, ten Hacken NH, van den Berge M. Asthma and chronic obstructive pulmonary disease: similarities and differences. Clin Chest Med. 2014;35(1):143-156.

2. van den Berge M, Kerstjens HA, Meijer RJ, et al. Corticosteroid-induced improvement in the PC20 of adenosine monophosphate is more closely associated with reduction in airway inflammation than improvement in the PC20 of methacholine. Am J Respir Crit Care Med. 2001; 164(7):1127-1132.

3. Christenson SA, Steiling K, van den Berge M, et al. Asthma-COPD overlap. Clinical relevance of genomic signatures of type 2 inflammation in chronic obstructive pulmonary disease. Am J Respir Crit Care Med. 2015;191(7):758-766.

4. Global Initiative for Asthma (GINA) Report. Global Strategy for Asthma Management and Prevention. http://www.ginasthma.org. 2015.

5. Global Strategy for Diagnosis, Management, and Prevention of COPD. http://www.goldcopd.org. 2015.

6. Definition and classification of chronic bronchitis for clinical and epidemiological purposes. A report to the Medical Research Council by their Committee on the Aetiology of Chronic Bronchitis. Lancet. 1965;1(7389):775-779.

7. Fabbri LM, Romagnoli M, Corbetta L, et al. Differences in airway inflammation in patients with fixed airflow obstruction due to asthma or chronic obstructive pulmonary disease. Am J Respir Crit Care Med. 2003;167(3):418-424.

8. de Oca MM, Halbert RJ, Lopez MV, et al. The chronic bronchitis phenotype in subjects with and without COPD: the PLATINO study. Eur Respir J. 2012;40(1):28-36.

9. Burgel PR, Nesme-Meyer P, Chanez $\mathrm{P}$, et al. Cough and sputum production are associated with frequent exacerbations and hospitalizations in COPD subjects. Chest. 2009;135(4):975-982.

10. Vestbo J, Prescott E, Lange P; Copenhagen City Heart Study Group. Association of chronic mucus hypersecretion with FEV1 decline and chronic obstructive pulmonary disease morbidity. Am J Respir Crit Care Med. 1996;153(5):1530-1535.

11. Lange P, Parner J, Vestbo J, Schnohr P, Jensen G. A 15-year follow-up study of ventilatory function in adults with asthma. $N$ Engl J Med. 1998;339(17):1194-1200.

12. Watson L, Vestbo J, Postma DS, et al. Gender differences in the management and experience of Chronic Obstructive Pulmonary Disease. Respir Med. 2004;98(12):1207-1213. 
13. Kitaguchi Y, Komatsu Y, Fujimoto K, Hanaoka M, Kubo K. Sputum eosinophilia can predict responsiveness to inhaled corticosteroid treatment in patients with overlap syndrome of COPD and asthma. Int J Chron Obstruct Pulmon Dis. 2012;7:283-289.

14. Bergeron C, Tulic MK, Hamid Q. Airway remodelling in asthma: from benchside to clinical practice. Can Respir J. 2010;17(4):e85-e93.

15. Benayoun L, Druilhe A, Dombret MC, Aubier M, Pretolani M. Airway structural alterations selectively associated with severe asthma. Am J Respir Crit Care Med. 2003;167(10):1360-1368.

16. Vonk JM, Jongepier H, Panhuysen CI, Schouten JP, Bleecker ER, Postma DS. Risk factors associated with the presence of irreversible airflow limitation and reduced transfer coefficient in patients with asthma after 26 years of follow up. Thorax. 2003;58(4):322-327.

17. Contoli M, Baraldo S, Marku B, et al. Fixed airflow obstruction due to asthma or chronic obstructive pulmonary disease: 5-year follow-up. J Allergy Clin Immunol. 2010;125(4):830-837.

18. Tashkin DP, Celli B, Senn S, et al. A 4-year trial of tiotropium in chronic obstructive pulmonary disease. $N$ Engl J Med. 2008; 359(15):1543-1554.

19. Albert P, Agusti A, Edwards L, et al. Bronchodilator responsiveness as a phenotypic characteristic of established chronic obstructive pulmonary disease. Thorax. 2012;67(8):701-708.

20. Papi A, Romagnoli M, Baraldo S, et al. Partial reversibility of airflow limitation and increased exhaled NO and sputum eosinophilia in chronic obstructive pulmonary disease. Am J Respir Crit Care Med. 2000;162(5):1773-1777.

21. Bleecker ER, Emmett A, Crater G, Knobil K, Kalberg C. Lung function and symptom improvement with fluticasone propionate/salmeterol and ipratropium bromide/albuterol in COPD: response by beta-agonist reversibility. Pulm Pharmacol Ther. 2008;21(4):682-688.

22. Kitaguchi Y, Fujimoto K, Kubo K, Honda T. Characteristics of COPD phenotypes classified according to the findings of HRCT. Respir Med. 2006;100(10):1742-1752.

23. Reid DW, Wen Y, Johns DP, Williams TJ, Ward C, Walters EH. Bronchodilator reversibility, airway eosinophilia and anti-inflammatory effects of inhaled fluticasone in COPD are not related. Respirology. 2008;13(6):799-809

24. Perng DW, Wu CC, Su KC, Lee YC, Perng RP, Tao CW. Inhaled fluticasone and salmeterol suppress eosinophilic airway inflammation in chronic obstructive pulmonary disease: relations with lung function and bronchodilator reversibility. Lung. 2006;184(4):217-222.

25. O’Byrne P M, Postma DS; Asthma Research Group. The many faces of airway inflammation. Asthma and chronic obstructive pulmonary disease. Am J Respir Crit Care Med. 1999;159(5 Pt 2): S41-S63.

26. van den Berge M, Vonk JM, Gosman M, et al. Clinical and inflammatory determinants of bronchial hyperresponsiveness in COPD. Eur Respir J. 2012;40(5):1098-1105.
27. Tashkin DP, Altose MD, Bleecker ER, et al; The Lung Health Study Research Group. The lung health study: airway responsiveness to inhaled methacholine in smokers with mild to moderate airflow limitation. Am Rev Respir Dis. 1992;145(2 Pt 1):301-310.

28. Postma DS, Wempe JB, Renkema TE, van der Mark TW, Koeter GH. Hyperresponsiveness as a determinant of the outcome in chronic obstructive pulmonary disease. Am Rev Respir Dis. 1991;143(6):1458-1462.

29. Postma DS, Kerstjens HA. Characteristics of airway hyperresponsiveness in asthma and chronic obstructive pulmonary disease. Am J Respir Crit Care Med. 1998;158(5 Pt 3):S187-S192.

30. Xu X, Rijcken B, Schouten JP, Weiss ST. Airways responsiveness and development and remission of chronic respiratory symptoms in adults. Lancet. 1997;350(9089):1431-1434.

31. Postma DS, de Vries K, Koeter GH, Sluiter HJ. Independent influence of reversibility of air-flow obstruction and nonspecific hyperreactivity on the long-term course of lung function in chronic air-flow obstruction. Am Rev Respir Dis. 1986;134(2):276-280.

32. Rutgers SR, Koeter GH, van der Mark TW, Postma DS. Short-term treatment with budesonide does not improve hyperresponsiveness to adenosine $5^{\prime}$-monophosphate in COPD. Am J Respir Crit Care Med. 1998;157(3 Pt 1):880-886.

33. Hardin M, Cho M, McDonald ML, et al. The clinical and genetic features of COPD-asthma overlap syndrome. Eur Respir J. 2014; 44(2):341-350.

34. Kauppi P, Kupiainen H, Lindqvist A, et al. Overlap syndrome of asthma and COPD predicts low quality of life. J Asthma. 2011; 48(3):279-285.

35. Fu JJ, Gibson PG, Simpson JL, McDonald VM. Longitudinal changes in clinical outcomes in older patients with asthma, COPD and asthmaCOPD overlap syndrome. Respiration. 2014;87(1):63-74.

36. Tashkin DP, Chipps BE, Trudo F, Zangrilli JG. Fixed airflow obstruction in asthma: a descriptive study of patient profiles and effect on treatment responses. J Asthma. 2014;51(6):603-609.

37. Lim HS, Choi SM, Lee J, et al. Responsiveness to inhaled corticosteroid treatment in patients with asthma-chronic obstructive pulmonary disease overlap syndrome. Ann Allergy Asthma Immunol. 2014; 113(6):652-657.

38. Jones RC, Price D, Ryan D, et al. Opportunities to diagnose chronic obstructive pulmonary disease in routine care in the UK: a retrospective study of a clinical cohort. Lancet Respir Med. 2014;2(4):267-276.

39. Pascoe S, Locantore N, Dransfield MT, Barnes NC, Pavord ID. Blood eosinophil counts, exacerbations, and response to the addition of inhaled fluticasone furoate to vilanterol in patients with chronic obstructive pulmonary disease: a secondary analysis of data from two parallel randomised controlled trials. Lancet Respir Med. 2015;3(6)435-442.

40. Brightling CE, McKenna S, Hargadon B, et al. Sputum eosinophilia and the short term response to inhaled mometasone in chronic obstructive pulmonary disease. Thorax. 2005;60(3):193-198.

Journal of Asthma and Allergy

\section{Publish your work in this journal}

The Journal of Asthma and Allergy is an international, peer-reviewed open-access journal publishing original research, reports, editorials and commentaries on the following topics: Asthma; Pulmonary physiology; Asthma related clinical health; Clinical immunology and the immunological basis of disease; Pharmacological interventions and

new therapies. Issues of patient safety and quality of care will also be considered. The manuscript management system is completely online and includes a very quick and fair peer-review system, which is all easy to use. Visit http://www.dovepress.com/testimonials.php to read real quotes from published authors. 